\title{
Learning Strategies Applied by Students at University Level
}

\author{
Agnieszka Uberman \\ University of Rzeszów, Rzeszów, Poland
}

\begin{abstract}
The presentation aims at addressing the most frequently applied strategies for language learning adopted by Polish students of English at the university level. For the purpose of data collection, R. Oxford's Strategy Inventory for Language Learning (SILL) is adopted. The analysis is an attempt at identifying common existing patterns or preferred ways of language processing among learners at advanced level of language mastery.
\end{abstract}

Keywords: learning strategies, advanced foreign language students, SILL

\section{Introduction}

Foreign language learners employ a variety of tactics to deal with the new input and language material. Some of them are intuitive, while others demand a certain degree of skill and manipulation to yield desired results. In the following discussion attention shall focus on the analysis of language learning strategies as adopted and put in use by Polish students of English at university level.

\section{Learning Strategies-Typology}

Strategies adopted in the process of language acquisition and learning have been extensively discussed by scholars in the field. Brown (2000) pointed out that while

Styles are general characteristics that differentiate one individual from another; strategies are those specific 'attacks' that we make on a given problem. They are the moment-by-moment techniques that we employ to solve 'problems' posed by second language input and output. (2000, p. 122)

Learning strategies, in contrast to general styles, are thus defined as "specific actions, behaviors, steps, or techniques - such as seeking out conversations partners, or giving oneself encouragement to tackle a difficult language task — used by students to enhance their own learning" (Scarcella \& Oxford, 1992, p. 63). Their importance for language learning lies in their active application intended for "self-directed involvement, which is essential for developing communication ability" (Scarcella \& Oxford, 1992, p. 63).

The awareness of the special tactics applied in different learning situations has enabled researchers to specify "good" or "successful" learner characteristics. They are grouped into metacognitive, cognitive, and socioaffective strategies (O’Malley, Chamot, Stewner-Manzanares, Russo, \& Kupper, 1985; O’Malley \& Chamot, 1990). The group of metacognitive strategies combines the learning procedures which refer to planning, monitoring, as well as evaluating a given learning activity. Cognitive strategies pertain to particular learning tasks and "involve more direct manipulation of the learning material itself" (Brown, 2000, p. 124), while the socioaffective group refers to social mediation and interaction with others. Participants in the 
communication process frequently need to resort to various communication strategies to manage the interaction successfully. They rest on the application of verbal and/or non-verbal means to convey intended meanings effectively. The collection covers compensatory as well as avoidance strategies (Dörney, 1995).

For the purpose of the present study, R. Oxford's (1990) strategy classification system has been employed. The identified language learning strategies are gathered into two classes: direct and indirect, with each class further subdivided into three groups of strategies. Hence the direct class contains memory, cognitive, and compensation strategies, while metacognitive, social, and affective strategies are categorised as members of the indirect class.

Oxford (2001) pointed out that "language learning styles and strategies are among the main factors that help determine how- and how well- our students learn a second or foreign language" (p. 359). The present discussion is not intended to revolutionise the field of research by providing alternative classifications or typologies. Instead, it aims at showing how the strategies are applied by Polish advanced EFL (English as a Foreign Language) learners in their daily language study and practice.

\section{Group Description and Methodology of Research}

The students who participated in the present research study are in their bachelor programme at the University of Rzeszów. They have reached advanced level of foreign language proficiency. Young individuals have by now already discovered their own preferred ways of knowledge acquisition and language study.

One hundred students took part in the study. They were requested to respond to a series of statements presented in the form of a questionnaire designed by R. Oxford (1989), namely Strategy Inventory for Language Learning version (7.0 ESL/EFL - in Appendix). The questionnaire was designed to provide information concerning the manner in which foreign language students deal with language learning tasks. It is composed of 50 statements divided into six parts (strategy groups), each of which demands the respondent to familiarise him/herself with the statements related to learning techniques employed by individuals in the process of foreign language study on their way towards language mastery. They are requested to verify each statement by stating whether it is:

A. Never true of me (also including the option almost never true of me);

B. Usually not true of me;

C. Somewhat true of me;

D. Usually true of me;

E. Always true of me (also including the option almost always true of me).

The respondents are to select appropriate responses by referring to the frequency of occurrence of the described situation or action performed by an individual in their learning behaviour.

\section{Data Analysis}

As pointed out above, 100 respondents took part in the research study. Therefore, wherever the number is provided in the discussion of the obtained result, it is simultaneously understood as percentage point as well provided for a given statement in the questionnaire (specific data in Table 1). 
Table 1

Number of Responses Provided for Each Statement

\begin{tabular}{|c|c|c|c|c|c|c|}
\hline $\begin{array}{ll} & \text { Student's response } \\
\text { Question No. } & \\
\end{array}$ & A & $\mathrm{B}$ & $\mathrm{C}$ & $\mathrm{D}$ & $\mathrm{E}$ & $\begin{array}{l}\text { No response } \\
\text { provided }\end{array}$ \\
\hline \multicolumn{7}{|l|}{ Part A—memory strategies } \\
\hline 1 & 5 & 13 & 24 & 41 & 16 & 1 \\
\hline 2 & 5 & 21 & 25 & 37 & 12 & - \\
\hline 3 & 12 & 18 & 23 & 32 & 15 & - \\
\hline 4 & 12 & 15 & 26 & 27 & 20 & - \\
\hline 5 & 44 & 28 & 21 & 4 & 3 & - \\
\hline 6 & 35 & 32 & 19 & 11 & 3 & - \\
\hline 7 & 51 & 19 & 14 & 14 & 2 & - \\
\hline 8 & 8 & 22 & 42 & 22 & 6 & - \\
\hline 9 & 5 & 8 & 7 & 38 & 42 & - \\
\hline \multicolumn{7}{|l|}{ Part B-cognitive strategies } \\
\hline 1 & 3 & 11 & 13 & 42 & 29 & 2 \\
\hline 2 & 6 & 4 & 21 & 39 & 30 & - \\
\hline 3 & 4 & 8 & 25 & 43 & 20 & - \\
\hline 4 & 3 & 19 & 39 & 28 & 11 & - \\
\hline 5 & 4 & 15 & 29 & 39 & 12 & 1 \\
\hline 6 & 1 & 5 & 24 & 34 & 34 & 2 \\
\hline 7 & 6 & 15 & 29 & 33 & 17 & - \\
\hline 8 & 13 & 14 & 27 & 32 & 13 & 1 \\
\hline 9 & 9 & 13 & 31 & 24 & 22 & 1 \\
\hline 10 & 7 & 23 & 22 & 31 & 17 & - \\
\hline 11 & 1 & 18 & 32 & 36 & 13 & - \\
\hline 12 & 12 & 19 & 37 & 23 & 9 & - \\
\hline 13 & 6 & 17 & 29 & 31 & 17 & - \\
\hline 14 & 19 & 22 & 28 & 23 & 8 & - \\
\hline \multicolumn{7}{|l|}{ Part C-compensation strategies } \\
\hline 1 & 5 & 13 & 32 & 33 & 17 & - \\
\hline 2 & 7 & 28 & 34 & 24 & 7 & - \\
\hline 3 & 25 & 31 & 24 & 15 & 5 & - \\
\hline 4 & 1 & 13 & 19 & 45 & 22 & - \\
\hline 5 & 11 & 25 & 31 & 27 & 6 & - \\
\hline 6 & 2 & 5 & 10 & 35 & 48 & - \\
\hline \multicolumn{7}{|l|}{ Part D_metacognitive strategies } \\
\hline 1 & 3 & 11 & 31 & 41 & 14 & - \\
\hline 2 & 3 & 8 & 17 & 48 & 24 & - \\
\hline 3 & 0 & 4 & 4 & 38 & 53 & 1 \\
\hline 4 & 2 & 8 & 22 & 41 & 26 & 1 \\
\hline 5 & 10 & 28 & 27 & 21 & 12 & 2 \\
\hline 6 & 13 & 12 & 38 & 24 & 12 & 1 \\
\hline 7 & 1 & 13 & 36 & 35 & 14 & 1 \\
\hline 8 & 1 & 8 & 36 & 34 & 20 & 1 \\
\hline 9 & 2 & 9 & 15 & 43 & 30 & 1 \\
\hline
\end{tabular}


(table 1 continued)

\begin{tabular}{|c|c|c|c|c|c|c|}
\hline $\begin{array}{ll} & \text { Student's response } \\
\text { Question No. } & \end{array}$ & A & B & $\mathrm{C}$ & $\mathrm{D}$ & $\mathrm{E}$ & $\begin{array}{l}\text { No response } \\
\text { provided }\end{array}$ \\
\hline \multicolumn{7}{|l|}{ Part E-affective strategies } \\
\hline 1 & 7 & 16 & 27 & 28 & 21 & 1 \\
\hline 2 & 4 & 9 & 26 & 37 & 24 & - \\
\hline 3 & 27 & 19 & 27 & 19 & 8 & - \\
\hline 4 & 15 & 20 & 27 & 25 & 13 & - \\
\hline 5 & 82 & 10 & 4 & 4 & - & - \\
\hline 6 & 52 & 18 & 13 & 12 & 5 & - \\
\hline \multicolumn{7}{|l|}{ Part F-social strategies } \\
\hline 1 & 4 & 12 & 16 & 39 & 28 & 1 \\
\hline 2 & 12 & 21 & 21 & 26 & 20 & - \\
\hline 3 & 5 & 13 & 19 & 38 & 25 & - \\
\hline 4 & 12 & 18 & 23 & 30 & 17 & - \\
\hline 5 & 4 & 8 & 19 & 42 & 26 & 1 \\
\hline 6 & 1 & 13 & 27 & 33 & 26 & - \\
\hline
\end{tabular}

Part A comprises nine statements referring to direct memory strategies. Nearly half of the questionnaire respondents (41\%) usually think of the relationships between what they already know and the new things they are learning in English. The association is always made by $16 \%$ of the analysed population, thus representing a strong pattern of language learning behaviour. This pattern is also a fairly regular one for a quarter of the research group (24\%).

The newly acquired language material in the form of lexical items is employed in sentences for better retention by three quarters of the respondent group. Twenty-five percent of polled students fairly regularly use new English words in a sentence to remember them, while the same strategy is employed regularly by 37 students and it constitutes a strong learning behaviour for 12 language learners.

While considering the strategy I connect the sound of an English word and an image or picture of the word to help me remember the word, a third of the group denied the regular and frequent application of this tactic (12\%-never true of me; $18 \%$ - usually not true of me). However, a form of visual representation or acoustic association is employed by a large majority of the group. It is adopted regularly by $32 \%$ of the research group and it constitutes a strong pattern of learning behaviour for 15 students. Similar responses were provided for the strategy of creating a mental picture of the situation where the given items can be employed as a way to memorise the new lexical items $(12 \%$-never true of me; $15 \%$ - usually not true of me; $26 \%$-somewhat true of me; $27 \%$ - usually true of me; $20 \%$ - always true of me).

The use of rhymes as a facilitating technique in remembering new English words is not universally adopted by the research group members. It can be considered a strong and regular language learning pattern for merely $7 \%$ of the population, while $44 \%$ never adopt it as a learning strategy and it is usually not true of $28 \%$ of respondents.

The application of flashcards in order to memorise novel vocabulary is a similarly infrequent strategy. For $19 \%$ of respondents, it can be considered a fairly regular pattern, while only $11 \%$ regularly employ it in the course of study, and for only $3 \%$, it represents a strong pattern in their learning behaviour. The remaining majority never (35\%) or hardly ever (32\%) resort to this type of memorising tactics. 
Physically acting out new lexemes can be treated as a strategy that has little reflection in students' language learning behaviour. It is practised fairly regularly by $13 \%$ of the research group members and it is an obvious $(14 \%)$ or strong (2\%) pattern for less than a fifth of the total population. This technique is employed only infrequently by $19 \%$ of respondents, while $51 \%$ claim they never report to this form of learning pattern.

Revision is generally considered as a successful form of committing the newly introduced language forms to memory. Thus, revising the lesson material is a recurring learning pattern utilised frequently by over $60 \%$ or the research group members (for $42 \%$ it is a fairly regular pattern, while it represents an obvious or strong one for $21 \%$ and $6 \%$ of questionnaire respondents respectively).

Not surprisingly, a vast majority of language learners taking part in this research study employ the strategy of memorising new words or phrases by remembering their location on the page, on the board, or on a street sign. In various classrooms, statistically most learners are visual learners whose learning abilities are boosted when supplemented by some form of visual representation of the introduced language material. Eighty percent of the total number of study participants regularly utilise this form of memory training combined with lexical acquisition; for $38 \%$, this strategy is a regular feature of their learning process, while $42 \%$ state it is always true of them. Only a fifth of the research population employs this technique infrequently.

In the following part of the research study, respondents were addressing their use of direct cognitive strategies.

Students were asked to state whether they say or write new English words several times. This is also a popular strategy, the application of which enables language learners to retain the acquired material for a longer period of time and commit it to the active lexical stock. Two respondents failed to make any choice and the remaining group qualified it as recurrent (13\%) or very frequent ( $42 \%$ and $29 \%)$. Three students claimed never to use this form of language behaviour while 11 students stated they apply it only occasionally.

Putting acquired knowledge and skills into practical use is one of many ways of consolidating the new abilities and trying them out in order to see whether the communicative aims can be reached. Language students seem to be well aware of this faculty as only $10 \%$ of the total studied population either never $(6 \%)$ or occasionally (4\%) try to talk like native English speakers. This strategy is quite regularly adopted by $21 \%$ of respondents and it is universally employed by nearly $40 \%$ of students. Thirty percent of the polled group stated it happens almost all the time and it represents a strong pattern in their learning behaviour. A similar response pattern is visible for the strategy of practising the sounds of English $(4 \%-8 \%-25 \%-43 \%-20 \%)$, while the use of familiar English lexical items in different ways is a less often utilised procedure. The responses range from usually not true of me (19\%), through somewhat true of me (39\%) to usually true of me (28\%). Very few students $(3 \%)$ avoid the application of this technique and a relatively small group (11\%) considers it to be a very significant procedure in their foreign language learning process. I start conversations in English is a strategy that seems to follow a very similar pattern and response range $(4 \%-15 \%-29 \%-39 \%-11 \%)$, however, it is not as recurrent in students' language learning practice as watching TV programmes or films in their original language version. The students who engage in the exploration of authentic materials (either films and shows or books and magazines) develop their language sensitivity and are exposed to the language input that has been created with language users and not language learners in mind. As gathered responses show, watching shows or films is a preferred form of language exposure $(1 \%-5 \%-24 \%-34 \%-34 \%)$ as compared to reading for pleasure in English $(6 \%-15 \%-29 \%-33 \%-17 \%)$. It has to be stressed, however, that both 
forms of authentic language application enjoy a relatively high degree of interest on the part of foreign language students. They do appear as significant strategies willingly exploited by language learners.

The decline in figures is even more visible $(13 \%-14 \%-27 \%-32 \%-13 \%)$ where producing written language is concerned; it is apparent that students prefer engaging in the oral input rather than written output. This is not the case of oral production, however. As the above discussion points out, foreign language learners willingly engage in conversations and oral practice.

The strategy of skimming the written passage first and rereading for further details is a popular technique among questionnaire respondents. Only a fifth of the research group infrequently make use of this strategy, while the vast majority make regular use of this learning pattern $(31 \%-24 \%-22 \%)$.

Learners try to find associations for new lexical items in their native language to aid the process of memorising the former $(7 \%-23 \%-21 \%-31 \%-17 \%)$, but a more advanced strategy of trying to find patterns in English is employed more frequently by a significant number of respondents. Thirty-two percent claim they adopt this strategy quite often, while $36 \%$ consider it an obvious pattern in their language behaviour with $13 \%$ pointing to this strategy as always true of me. Fewer than $20 \%$ of the research group does not make a frequent application of this learning procedure.

Breaking lexical items down into manageable units is statistically less frequently adopted than the strategy of finding patterns in English, yet it is still a relatively recurrent strategy. Twelve percent of respondents deny ever using it and 19\% admit they do adopt this procedure, however, it is rarely implemented. Nevertheless, it appears to be quite beneficial as $37 \%$ of research group members state they sometimes resort to this strategy in the process of deducing the meaning of new lexical items, $23 \%$ do it often, while it is a regular practice for only $9 \%$ of study participants.

Advanced learners are generally characterised by the awareness of the nuances and differences between meanings embodied in lexical items in their mother tongue and the foreign language they want to master. Therefore, it is hardly surprising that they try not to translate word-for-word. The strategy under consideration is avoided by $6 \%$ of the research group and it is employed only infrequently by $17 \%$ of the polled students. Nearly $30 \%$ occasionally make use of the procedure, while for nearly $50 \%$ of the respondents state this seems to be a natural pattern in the process of language learning.

The least often adopted strategy of the set of cognitive procedures is the one exemplified in the statement: I make summaries of information that I hear or read in English. Over $40 \%$ of respondents never or hardly ever implement this procedure. As few as $8 \%$ regularly adopt it while learning, however, over $50 \%$ of researched students exploit this strategy occasionally or regularly.

Part $\mathrm{C}$ of the employed research tool focuses on the application of direct compensation strategies.

The English lexicon can pose a considerable difficulty for foreign language learners in the process of decoding meanings of unfamiliar items. On some occasions, learners need to deduce the meaning from the context in which an item is embedded or make guesses. This procedure is very frequently utilised by advanced learners who are already equipped with ample lexical knowledge and can derive unknown senses engulfed in concepts with which they are faced. Over $80 \%$ of the respondents repeatedly employ this form of deducing meaning and only $18 \%$ state this strategy is rarely or never put to use.

Word recognition, however, is a less demanding process than language production. When asked to range the frequency of using gestures when at a loss for words in a conversation, learners' responses exhibit a lower 
frequency of application. Twenty-eight percent use the strategy only occasionally and $34 \%$ often adopt this procedure to arrive at intended meaning, while $24 \%$ employ it regularly. The remaining $14 \%$ of respondents either never (7\%) or always (7\%) do it. A more sophisticated form of paraphrase is adopted very regularly by a significant group or research participants: For $47 \%$, this strategy represents a strong pattern in their learning behaviour and it is almost always applied by $35 \%$ of the students.

Linguistic creativity in the form of making up new words if the appropriate English lexeme is not available is advocated by relatively few researched students. Fifteen percent state it is usually true of them and only $5 \%$ believe it is always the case. Of the remaining group only $24 \%$ claim they sometimes make up new words if they do not know the right ones in English and the rest (i.e., 56\%) either very rarely or never employ this strategy in the process of language learning.

Tolerance of ambiguity is one of the features of a successful language learner. The presence of this characteristic trait can be attributed to language users who can read texts without checking every unfamiliar item in a dictionary or a reference work of another kind. Questionnaire respondents seem to be advanced enough to quite willingly utilise this strategy, for two thirds of the researched group consider this an obvious language learning behaviour (45\%-usually true of me; $22 \%$ - always true of me). Nearly $20 \%$ of respondents stress that they read English texts without looking up every new word in a fairly regular pattern, while the remaining $14 \%$ are reluctant to adopt this strategy in their language learning process. Respondents also reasonably regularly try to guess what then other person will say next in English. This anticipation strategy, however, is more demanding as it requires careful processing of the incoming utterance. Nevertheless, $31 \%$ of the polled students quite commonly adopt this strategy in their learning behaviour, $27 \%$ use it very frequently, and $6 \%$ state it is always true of them. Still, a quarter of the investigated group applies the procedure under consideration irregularly, while $11 \%$ never seem to resort to this language learning strategy.

Many students try to organise their learning process in such a way that it is efficient and helps them become more successful and competent language users. They try not only to perform language tasks appropriately but also to arrange for additional contact with the foreign language and create opportunities to communicate and interact. Moreover, they consider the process of learning itself as well as its effectiveness. This is achieved by applying indirect metacognitive strategies (centering, arranging and planning, as well as evaluating own learning).

Over $85 \%$ of the questionnaire respondents state that they try to find diverse possibilities to use their English (sometimes-31\%; often - 41\%; always-14\%), which contributes to the development and facilitation of communication skills. An even higher percentage of the polled students self-evaluate their own performances in order to improve their future language competence. As many as $48 \%$ of respondents often notice their own language mistakes and use this information to help them advance. The same is recurrently done by $24 \%$ of the polled group, while $17 \%$ sometimes resort to this learning strategy. A surprisingly low percentage (3\%-never; $8 \%$ - hardly ever) of the research group avoid the application of the discussed learning pattern.

It is hardly surprising that over $90 \%$ of the polled student group pay attention when someone is speaking English. Over $50 \%$ consider this strategy a very strong learning behaviour and nearly $40 \%$ of respondents very frequently adopt this learning procedure to develop own language awareness and proficiency.

Students also eagerly engage in diverse forms of self-development and employ language improvement techniques. Over $20 \%$ admit they frequently try to find out how to be a better learner of English, while $41 \%$ 
implement this strategy very often and a further $26 \%$ state they adopt it repeatedly and it represents a strong learning pattern. Students are less likely to plan their schedule in order to provide ample time for the study of English. This is infrequent practice for almost $40 \%$ of the researched population and nearly $50 \%$ implement this strategy quite frequently, while only $12 \%$ state this is their regular practice. A higher percentage of positive responses are noted in case of providing for opportunities to communicate in English. Only $25 \%$ of respondents infrequently make use of this strategy, the remaining group members employ this learning practice fairly regularly, and for $12 \%$, this is a leading learning habit. Oral production skills practice is surpassed in frequency of application by extensive reading skills practice. Almost $85 \%$ of the researched group members pursue opportunities to read as much as possible in English. Applying this strategy ensures overall linguistic development and raises a learner's awareness of language structures, lexical relations, discourse features, and cultural notions embedded in the analysed texts. As few as $14 \%$ of the research study group seem to consider this form of language practice as insignificant, for it is implemented only infrequently.

Advanced-level learners have proved responsible enough to provide for opportunities to practise language as well as to consciously consider own language development. Over a third (36\%) of the researched group often set clear goals for improving own English skills, while this strategy is recurrently applied as a regular learning behaviour by $54 \%$ of the polled group. Only $10 \%$ of the analysed population seldom relies on such practices.

An even stronger tendency can be observed in the case of considering own progress, as nearly three quarters of the research group members resort to this learning strategy very regularly - it is an obvious learning behaviour for $43 \%$ and a strong pattern for $30 \%$ of the group under discussion.

Learners also deliberately employ techniques which help them ease the tension related to language production. The use of indirect affective strategies is considered in Part $\mathrm{E}$ of the questionnaire. Majority of the group undergoing analysis try to relax whenever they feel afraid of using English. Twenty-seven percent of the polled students quite regularly employ this learning behaviour, for $28 \%$, this is an obvious pattern, while $21 \%$ implement this procedure as an inevitable element of the learning process. Considerably, more students encourage themselves to speak despite the fear of producing erroneous language forms. This is a very strong tendency for almost $60 \%$ of the researched population, while approximately every fourth respondent (26\%) exercises this strategy quite frequently. Foreign language learners who were subjected to the analysis do not seem to be driven by external rewards for achieving success, thus the evidence of own progress appears to be valuable enough. Fewer than $30 \%$ of respondents regularly reward themselves when they do well in English and $27 \%$ sporadically employ this strategy. Learners equally infrequently acknowledge inner tension or the state of being nervous when studying English - 35\% of respondents never or hardly ever seem aware of this condition, while $13 \%$ always notice if they are tense or nervous. The remaining $52 \%$ of the respondents either quite frequently or often are aware of this psychosomatic condition.

Even though advanced students quite willingly employ various tactics to arrange for supportive learning environment, they are not used to writing a language learning diary. This strategy is definitely the most infrequently adopted learning behaviour, for $82 \%$ of respondents state they never write down their feelings in a language learning diary while $10 \%$ perform this strategy very rarely. Not a single student considers this learning behaviour a strong prerequisite for language learning and only four in 100 students often note down their current frame of mind in the form of a written record.

Relatively more respondents reflect on their feelings talking to someone else, this way proving the oral mode to be the favoured form of communication. The numbers are still not very significant as only $5 \%$ employ 
this strategy on a regular basis and $25 \%$ of respondents claim they implement this learning behaviour (fairly) often. The data, however, seem to show strong preference for oral communication over the written counterpart.

The obtained data point to the fact that students are reasonably skilled in the application of social strategies. A substantial majority of the analysed group members (nearly $70 \%$ ) regularly ask the interlocutor to repeat or paraphrase the miscomprehended utterance. Fewer students request to be corrected by English speakers, even though this strategy is a strong learning pattern for $45 \%$ of respondents (it is always true of $19 \%$ of the group) and $21 \%$ make frequent use of it. Not surprisingly, a significant proportion of the respondents states they practise English with other students owing to the fact that this is a strict requirement in most practical courses students attend at the university. Eighteen percent claim they never or rarely practise with peers, which is definitely an unexpectedly high percentage. Thirty percent of the polled group members do not request help from English speakers but nearly $40 \%$ do so recurrently. Questions are asked in English by a large proportion of the research group: $19 \%$ of respondents employ this strategy frequently, $42 \%$ very regularly, and this procedure is always implemented by $26 \%$ of the group members.

Students taking part in the study are all requested to study the culture of the English-speaking countries, as this is one of the core subjects in the teaching syllabus. Therefore, the negative responses provided in the questionnaire (14\% state they do not try to learn about the culture of the target language community) are a startling reply. While $27 \%$ assert they adopt this strategy in a fairly regular pattern, nearly $60 \%$ point to this procedure as a recurrent learning behaviour. Even though the number of negative responses constitutes a comparatively low percentage, this indicates that every sixth student disregards the significance of cultural background for the process of learning the language of the target community.

\section{Conclusion}

Advanced foreign language learners prove to be responsible for their learning and anticipated progress. They attempt to provide for ample opportunities to practise language, however, it can be noticed that the oral mode of communication is favoured over production expressed through the written mode. Learners willingly implement compensation strategies in order to facilitate interaction and ensure comprehension.

A repertoire of diverse learning strategies is recurrently employed to facilitate the learners' linguistic development. It can be easily noted that the polled group of students systematically employ memory strategies of creating mental linkages or reviewing well; however, the strategy of employing action: using physical response or sensation is generally avoided. Moderate interest is also visible for the implementation of the rhymes or flashcards even though many respondents seem to favour other memory strategies from the group of strategies applying images and sounds.

Direct cognitive strategies are most systematically implemented of all applied learning behaviour patterns. The analysed group of strategies enjoys a significant interest with the highest ranges of recurrent application.

Compensation strategies are hardly avoided by respondents. They appear to be quite sufficiently prepared to guess intelligently as well as to overcome limitations in speaking and writing. Students most frequently resort to using a circumlocution or synonym when they are faced with interaction problems. The opposite end of the frequency of use range is occupied by the strategy coining words, which seems to imply that language users considered in this study are not yet proficient enough to attempt this form of language creativity.

The most willingly implemented metacognitive strategies include paying attention, self-monitoring, finding out about language learning, as well as seeking practice opportunities, setting goals and objectives, and 
self-evaluating. Such an outcome is hardly surprising as the students are familiar with the best practices ensuring language development by participating in methodology of language learning/teaching courses. The data additionally seem to imply that respondents feel responsible for their progress and aware of the techniques that benefit their overall linguistic development.

It has to be noted that the affective strategies do not appear to hold a privileged position. Students are not inclined to either write down or talk to others about the feelings related to learning English. Rewarding oneself for achieving success is not particularly frequent, either. However, attempts are often made to lower one's anxiety as well as encourage oneself to produce language.

The final investigated group of social strategies asking for clarification or verification as well as asking questions followed by cooperating with peers display by far the greatest utility.

Language students are determined to develop their language proficiency and they employ a diverse range of learning tactics to facilitate the development of communicative competence.

Obviously, the above discussed tendencies are not universal because diverse groups of learners are affected by various factors such as age, the level of language mastery, or the purpose of studying English. Nevertheless, the data obtained for the researched group of advanced Polish students of English in the university setting reflect their significant language awareness and positive attitude towards the implementation of learning strategies to ensure foreign language progress.

\section{References}

Brown, H. D. (2000). Principles of language learning and teaching. White Plains, NY: Pearson Education.

Dörney, Z. (1995). On the teachability of communication strategies. TESOL Quarterly, 29, 55-84.

O’Malley, J. M., \& Chamot, A. U. (1990). Learning strategies in second language acquisition. Cambridge: Cambridge University Press.

O’Malley, J. M., Chamot, A. U., Stewner-Manzanares, G., Russo, R. P., \& Kupper, L. (1985). Learning strategy application with students of English as a second language. TESOL Quarterly, 19, 557-584.

Oxford, R. L. (1989). Strategy inventory for language learning (version 7.0 ESL/EFL). Retrieved from https://richarddpetty.files.wordpress.com/2010/03/sill-english.pdf

Oxford, R. L. (1990). Language learning strategies: What every teacher should know. Boston, MA: Heinle \& Heinle Publishers.

Oxford, R. L. (2001). Language learning styles and strategies. In M. Celce-Murcia (Ed.), Teaching English as a second or foreign language (pp. 359-366). Boston, MA: Heinle \& Heinle Publishers.

Scarcella, R. C., \& Oxford, R. L. (1992). The tapestry of language learning. The individual in the communicative classroom. Boston, MA: Heinle \& Heinle Publishers. 


\section{Appendix}

\section{Strategy Inventory for Language Learning (SILL) Version 7.0 (ESL/EFL)}

Read the item and choose a response ( 1 through 5 as below).

1. Never or almost never true of me

2. Usually not true of me

3. Somewhat true of me

4. Usually true of me

5. Always or almost always true of me

\section{Part A:}

1. I think of relationships between what I already know and new things I learn in English.

2. I use new English words in a sentence so I can remember them.

3. I connect the sound of a new English word and an image or picture of the word to help me remember the word.

4. I remember a new English word by making a mental picture of a situation in which the word might be used.

5. I use rhymes to remember new English words.

6. I use flashcards to remember new English words.

7. I physically act out new English words.

8. I review English lessons often.

9. I remember new English words or phrases by remembering their location on the page, on the board, or on a street sign.

\section{Part B:}

1. I say or write new English words several times.

2. I try to talk like native English speakers.

3. I practice the sounds of English.

4. I use the English words I know in different ways.

5. I start conversations in English.

6. I watch English language TV shows spoken in English or go to movies spoken in English.

7. I read for pleasure in English.

8. I write notes, messages, letters, or reports in English.

9. I first skim an English passage (read over the passage quickly), then go back and read carefully.

10. I look for words in my own language that are similar to new words in English.

11. I try to find patterns in English.

12. I find the meaning of an English word by dividing it into parts that I understand.

13. I try not to translate word-for-word.

14. I make summaries of information that I hear or read in English.

\section{Part C:}

1. To understand unfamiliar English words, I make guesses.

2. When I can't think of a word during a conversation in English, I use gestures.

3. I make up new words if I do not know the right ones in English.

4. I read English without looking up every new word.

5. I try to guess what the other person will say next in English.

6. If I can't think of an English word, I use a word or phrase that means the same thing. 


\section{Part D:}

1. I try to find as many ways as I can to use my English.

2. I notice my English mistakes and use that information to help me do better.

3. I pay attention when someone is speaking English.

4. I try to find out how to be a better learner of English.

5. I plan my schedule so I will have enough time to study English.

6. I look for people I can talk to in English.

7. I look for opportunities to read as much as possible in English.

8. I have clear goals for improving my English skills.

9. I think about my progress in learning English.

\section{Part E:}

1. I try to relax whenever I feel afraid of using English.

2. I encourage myself to speak English even when I am afraid of making a mistake.

3. I give myself a reward or treat when I do well in English.

4. I notice if I am tense or nervous when I am studying or using English.

5. I write down my feelings in a language learning diary.

6. I talk to someone else about how I feel when I am learning English.

\section{Part F:}

1. If I do not understand something in English, I ask the other person to slow down or say it again.

2. I ask English speakers to correct me when I talk.

3. I practice English with other students.

4. I ask for help from English speakers.

5. I ask questions in English.

6. I try to learn about the culture of English speakers. 